\title{
Performance Comparison of Different Wavelet Families Based on Vibration Damage Detection of a Timoshenko Beam
}

\author{
Arun Kumar $\mathrm{K}^{* 1}$ and Mallikarjuna Reddy $\mathbf{D}^{2}$ \\ ${ }^{*}$ Research Scholar, School of Mechanical Engineering, VIT University, Vellore, India. \\ ${ }^{2}$ Associate Professor, School of Mechanical Engineering, VIT University, Vellore, India.
}

\begin{abstract}
The objective of this work focuses on performance comparison of different wavelet families based on vibration damage detection in a Timoshenko beam structure. Module 1 considers only rotational damaged data only. Module 2 considers the difference data between undamaged and damaged beam structure. Wavelet properties are important factor for wavelet selection process to applicable area. The different types of continuous wavelet transform like daubechies, symlets, Coiflets, Gaussian, dmeyer, morlet, biorsplines, reverse bior are used. The rectangular beam is modeled numerically. The modal analysis is performed in a Timoshenko beam with two ends clamped boundary condition. The natural frequency and mode shapes of different damaged conditions are obtained. Damage is created by diminishing the young's modulus value percentage of single or multiple element, Rotational mode shape data's are effective in damage detection up to damage case 2 , and Difference data of rotational mode shape data's are effective all damage cases. Gaussian white noise SNR (Sound Noise ratio) 24 added with difference data, noise affected the damage detection algorithm performances in least damage case 6 and triple damage case 8 . Damage localize by sym3, dmey, bior6.8 wavelets are effective comparing to all other wavelet families. The absolute wavelet coefficients are used for damage localization and the maximum absolute wavelet coefficient are intended for identifying the damage severity.
\end{abstract}

Keywords: Symlets, Coiflets, Gaussian, Dmeyer, daubechies, morlet, Biorthogonal, Reverse Biorthogonal, Mode shapes, Natural frequency, Absolute wavelet coefficient

\section{INTRODUCTION:}

Damage detection in the structure is complicated process before last two decades, now the Vibration based damage detection techniques is much easier than the traditional method, If frequency and mode shape method failed to find defect, Combining older technique that is vibration theory and new technique that is wavelet transform make more comfort to solve the problem and ability produce good results. Damage in a structure will cause basic response annoyances at damage destinations. The displacement is investigated with the wavelet change and the nearness of the split is identified by a sudden change in the spatial variety of the changed response [3]. Amplitude and phase maps of the wavelet change are utilized as a part of conjunction to evaluate the state of an instrumented gear test rig. Phase wavelet guide and amplitude wavelet outline are quickly clarified, for locating the damage polar representation is best [4]. The affectability of wavelet strategy in the recognition of splits in bar structures and impacts of the diverse break qualities, limit conditions, and wavelet capacities utilized are explored. The two sorts of wavelets looked at in this examination are the Haar and Gabor wavelets. The results explores wavelet change is a valuable apparatus in location of splits in beam structures. The technique is delicate to the shape of the avoidance profile and is an element of the help condition. For location of discrete splits, Haar wavelets display predominant execution [6].

A straightforward technique for split recognizable proof in beam structures in view of wavelet investigation is introduced. The key vibration method of a damaged cantilever beam is dissected utilizing constant wavelet change and both the area and size of the damage are assessed. To assess the measure of the damage, wavelet coefficients are consider as list an incentive to speak to the damage. The proposed system is analyzed by both analytically and experimentally for a cantilever beam with transverse damage [7]. Continuous wavelet transforms having good potential over Fast Fourier Transform in damage detection. CWT is able to locate the damage in concrete [8]. Implement the wavelet transform technique in Timoshenko beam and proved this method is detecting the small size defect [9]. Double damaged beam structure considered damage is identified by symmlet wavelet. The area of the damage was dictated by the sudden changes in the spatial reaction of the changed flag at the site of the split. Such nearby changes ordinarily are not clear from the reaction information; they are, nonetheless, noticeable as singularities when utilizing wavelet examination because of its highdetermination properties. For the estimation of the relative profundity of the splits a power factor was built up. It relates the span of the splits to the comparing wavelet coefficients. It was demonstrated that the power factor changes with split profundity as per a second request polynomial law and along these lines, can be utilized as a marker for break degree [10]. Continuous wavelet transform are able to detect the multi damage present in the structure [11]. In a bridge like structure shows the effective of continuous wavelet transform in damage detection [13]. FRF curvature energy damage index method proposed for damage detection in plate like structures [16]. The strain energy data is used for wavelet transform and show the effectiveness of the wavelet transform in the damage detection in plate structure [17]. The numerical studies for damage detection in beam structure with mode shape curvatures and its spatial wavelet transforms are discussed 
[18]. Multi-span and multi-floor framed structures are considered and analyzed by means of a substructures approach, analyzing complicated structure experimentally is challenging and more sensors require [19]. Different wavelet families are compared and tested for bone vessel fusion [20].

In this analysis first five bending modes are studied, from the observation rotational mode shapes values are utilized through eight different wavelet families and find the optimum mode selection and optimum wavelet selection in damage detection on the beam structure. These results shows first mode and third mode is not effective, comparing to the all other modes. In this analysis different types of wavelet are tested, and based Absolute value of coefficient obtained from the damage location, all wavelets are compared and select suitable for future analysis. From the entire results shows sym3, Dmey and Bior 6.8 wavelets are all having a stability to detect the single and multiple damage for all different damage cases.

\section{FUNDAMENTAL OF WAVELET ANALYSIS:}

In utilizing the wavelet procedure, two vital numerical substances must be presented wavelet capacities and wavelet change. A complex-esteemed $\varphi(x)$ that is limited in both time and recurrence areas is utilized to make a group of wavelets $\varphi$ $\mathrm{e}, \mathrm{f}(\mathrm{x})$, where an and $\mathrm{b}$ are genuine numbers that widen (scale) and decipher the capacity $\varphi(x)$, individually these $\varphi(x)$ capacities are known as mother wavelets and can be persistent or discrete. For the constant case, the complex - esteemed wavelets created from the mother wavelet are given by

$$
\varphi_{e, f}(x)=|e|^{-1 / 2} \varphi\left(\frac{x-e}{e}\right)
$$

Where $\varphi$ is the mother wavelet, $\mathrm{j}$ the number expansion and whole number interpretation file. For given coordinated flag, the wavelet change acquired by incorporating the result of flag and the unpredictable conjugate wavelet work. The subsequent wavelet is the arrangement of wavelet coefficients is the measure of the relationship amongst wavelet and comparing wavelet flag. Numerically, consistent wavelet change, wf a,b of a $f(x)$ is characterized as

wf $a, b=1 / \sqrt{a} \int_{-\infty}^{\infty} f(x)\left(\frac{x-b}{a}\right) d x=\int_{-\infty}^{\infty} f(x) \varphi_{a, b}(x)$

The Gaussian family built function by taking the $p^{\text {th }}$ derivative of $f$.

$$
f(x)=c_{p \mathrm{e}^{-\mathrm{x}^{2}}}
$$

Wavelet coefficients are performed with different scale lists, nearby bothers in the mode shapes will be found in the fine scale wavelets that are situated at the areas of the annoyances.

The procedure of the damage detection is as follows [17]:

1) Find the first five bending mode shapes of the beam structure before and after damage.

2) Calculate the spatial wavelet coefficients of the mode shapes.

3) (3) Plot the estimation of Abs. Coefficient of various mother wavelets along the length of the beam.
4) Examine the disseminations of wavelet coefficients at each scale. A sudden change in the transients of the wavelet coefficients distinguishes the harm position.

5) Maximum wavelet coefficient introduce in the damaged area esteems demonstrates the harm seriousness

Usually Vibration depended damage detection techniques are required undamaged structure data, but it is very complicated in real time process, so wavelet based damage detection is very useful because it doesn't need of undamaged data, Here the objective of the work is identify the effectiveness of wavelet. In this case difference data is utilized to identify the minor damage also, and also avoid the boundary effect.

\section{NUMERICAL MODEL AND DAMAGE CASES:}
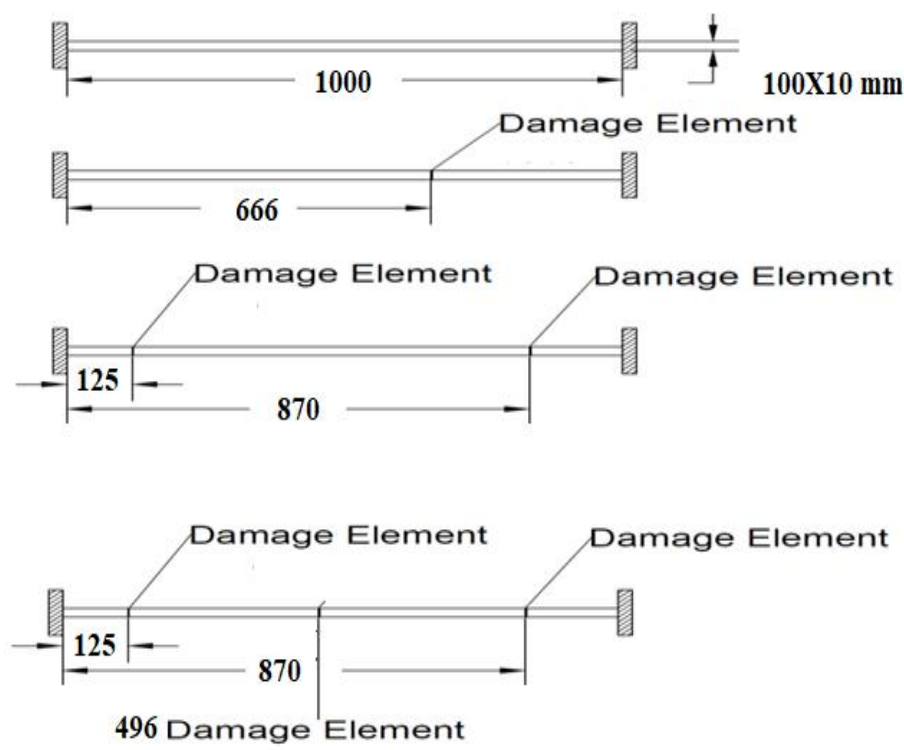

Figure 1: Single and multi - damage structure of beam (all dimensions are in $\mathrm{mm}$ )

Table 1. The various damaged cases with element details:

\begin{tabular}{|c|c|c|}
\hline Damage Cases & $\begin{array}{c}\text { \% of Young's } \\
\text { modulus reduction }\end{array}$ & $\begin{array}{c}\text { Damage element } \\
\text { number }\end{array}$ \\
\hline 1 & 90 & 666 \\
\hline 2 & 60 & 666 \\
\hline 3 & 40 & 666 \\
\hline 4 & 20 & 666 \\
\hline 5 & 10 & 666 \\
\hline 6 & 5 & 125,870 \\
\hline 7 & 50 & $125,496,870$ \\
\hline 8 & 50 & \\
\hline
\end{tabular}


International Journal of Applied Engineering Research ISSN 0973-4562 Volume 14, Number 14 (2019) pp. $3286-3295$

(C) Research India Publications. https://dx.doi.org/10.37622/IJAER/14.14.2019.3286-3295

Table 2. First five modes frequency comparison for both intact and various cases

\begin{tabular}{|c|c|c|c|c|c|}
\hline \multirow{2}{*}{$\begin{array}{c}\text { Damage } \\
\text { Cases }\end{array}$} & \multicolumn{5}{|c|}{ Frequency(Hz) for the mode number } \\
\cline { 2 - 6 } & $\mathbf{1}$ & $\mathbf{2}$ & $\mathbf{3}$ & $\mathbf{4}$ & $\mathbf{5}$ \\
\hline UD & 51.845 & 142.78 & 279.56 & 461.40 & 687.94 \\
\hline Case 1 & 51.716 & 141.73 & 279.43 & 459.27 & 682.53 \\
\hline Case 2 & 51.823 & 142.60 & 279.54 & 461.03 & 687.00 \\
\hline Case 3 & 51.835 & 142.70 & 279.55 & 461.24 & 687.52 \\
\hline Case 4 & 51.841 & 142.75 & 279.56 & 461.34 & 687.78 \\
\hline Case 5 & 51.843 & 142.77 & 279.56 & 461.37 & 687.86 \\
\hline Case 6 & 51.844 & 142.77 & 279.56 & 461.38 & 687.90 \\
\hline Case 7 & 51.809 & 142.78 & 279.47 & 460.90 & 686.82 \\
\hline Case 8 & 51.771 & 142.78 & 279.19 & 460.90 & 686.14 \\
\hline
\end{tabular}

Figure. 1 shows the undamaged rectangular beam structure and single, double and triple damaged beam structure and damaged element location is mentioned with element number. In this current work fixed -fixed beam with rectangular cross section $\mathrm{h}=0.01 \mathrm{~m}, \mathrm{~b}=0.001 \mathrm{~m}$, and length $1 \mathrm{~m}$ modeled in ANSYS 19. Modulus of elasticity is $68.9 \mathrm{Gpa}$, Poisson coefficient is 0.34 , density is $2700 \mathrm{~kg} / \mathrm{m}^{3}$ given as material properties. The 2 noded beam 188 is taken as element type it is very much suitable for Timoshenko beam with first order shear deformation theory. Length of the beam is divided into 1000 divisions and width of the beam is considered a single division. The total numbers of elements obtained are 1000 . The damage is created by diminishing the modulus of elasticity value of single or multiple locations in beam structure. Different damage cases and corresponding reducing in Young's modulus values are tabulated as shown in Table.1. The modal analysis is performed on the beam structure to estimate natural frequency, nodal displacements (rotational) values of damaged and undamaged and all cases. Table II shows the natural frequency reduction for different damage cases. It clearly denotes damage present in the structure. But this method is not able to locate the defect.

Natural frequency decreases in order to damage present in a beam structure, difference of the natural frequencies are calculated, for damage case 1(0.129), damage case 2(0.022), damage case $3(0.01)$, damage case $4(0.004)$, damage case $5(0.002)$, damage case 6(0.001), damage case 7(0.036), damage case $8(0.074)$, here damage case 1 is a single element damage with highest severity, showing higher difference in the meantime damage case $7 \& 8$ represents the double and triple element damage but it doesn't have considerable frequency change it clearly denotes natural frequency method is not effective for multi damage detection.

\section{RESULTS AND DISCUSSIONS}

\subsection{Module 1: Using damaged mode shape signal only}

The Rotational mode shapes are obtained by modal analysis. In this module only damaged rotational mode shape data only considered, because in the real time structure calculating undamaged data is very complicate to obtain. For damage case 1 rotational displacement pattern shows discontinuity in its slope so it is having potential to detect the damage spot but calculating damage size is complicated. But all other damages rotational mode shapes are not effective to locate damage because its damage severity is very much small so it doesn't have much influence in rotational mode patterns.

When the rotational mode shapes are fail to locate the damage different wavelet families are utilized to analyze the rotational mode shape in locally, it will analyze the signals and identify the transients in the signal that sharp peak shows the damage location that peak magnitude assumed to be damage severity. Combining rotational mode shape and different wavelets families will produce good results. So, this method is able to locate damage and its severity. Even this method is useful in multi crack detection also, proposed method predicts the crack even it is located near by the fixed boundary condition.

\subsubsection{Single damage location for damage case1}

First five rotational mode shapes are plotted for damage case 1 , to identify the mode shape sensitivity in damage detection.

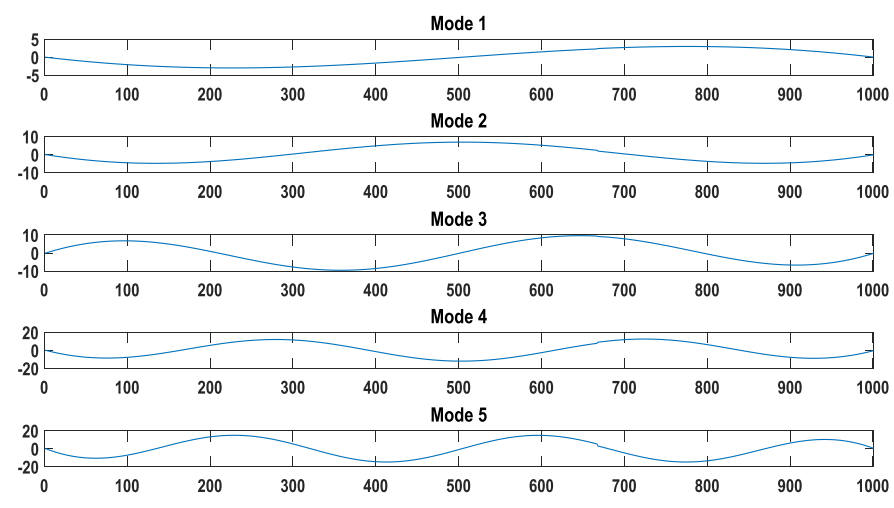

Figure 2. Fundamental rotational mode shape for damage case 1

Figure 2 shows the first five rotational mode shapes of damage case 1 , second and fifth mode is effective in both modes are showing small discontinuity in rotational mode shapes itself. But other mode shapes are not effective in damage detection. So consider second mode for single element damage fifth mode for multi damage case. Further this spatial data processed through the different wavelet families to detect the damage as well as performance comparison of different wavelet families. 


\subsubsection{Effective Mode selection:}

\subsubsection{First mode shape for Damage case 1:}

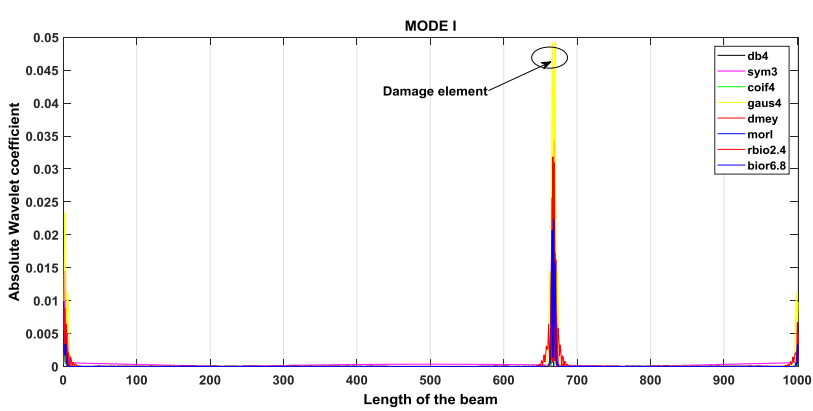

Figure 3. 2D plot of Abs. Coefficient along major axis of the beam for different wavelet families

Figure 3 shows the rotational mode shapes data for damage case 1 absolute wavelet coefficient of different wavelets are plotted along major axis of the beam to locate damage, peak magnitude signify damage location. Particularly in first mode gauss 4 is having high coefficient value and second Rbio 2.4 also high coefficient values but both wavelets are affected by the boundary problem. Sudden variation in stiffness leads this kind of problem.

\subsubsection{Second Mode shape for damage case 1}

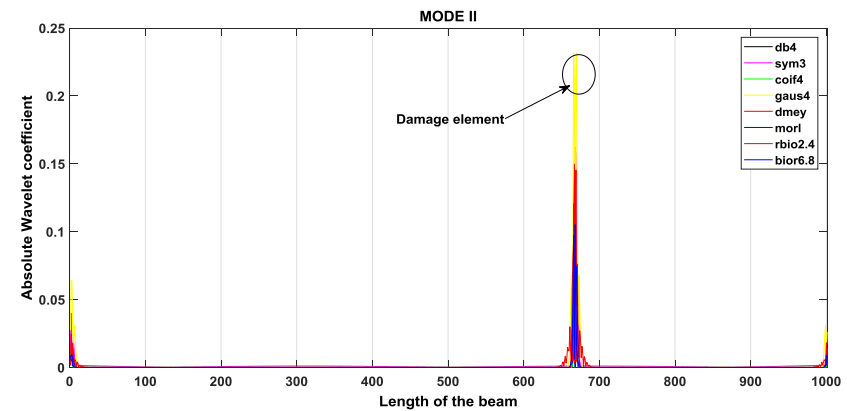

Figure 4. 2D plot of Abs. Coefficient along major axis of the beam for different wavelet families

Figure 4 shows the rotational modes shape data for damage case 1 data absolute wavelet coefficient of different wavelets are plotted along the major axis of the beam to locate damage, peak magnitude signify damage location. Second mode is very much sensible over all the modes in damage detection

\subsubsection{Third mode shape for damage case 1:}

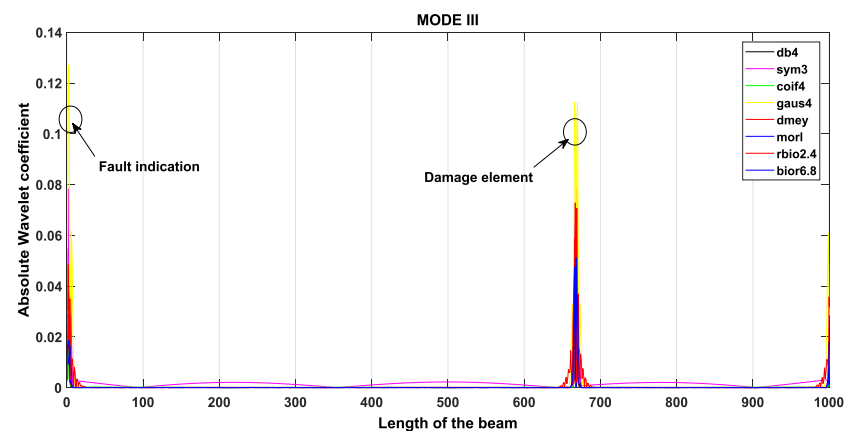

Figure 5. 2D plot of Abs. Coefficient along major axis of the beam for different wavelet families
Figure 5 shows the rotational modes shape data for damage case 1 absolute wavelet coefficient of different wavelets are plotted along major axis of the beam to locate damage; peak magnitude signify damage location. Third mode is less sensitive because the value produced nearby the value is too high so the algorithm will find the wrong location.

Yellow color peak is representing gaus4 wavelet it is producing larger value around the boundary in the same it does not have the scaling function so this is not suitable find the small damage. Rbio 2.4 also affected by the boundary effect.

\subsubsection{Fourth Mode shape for Damage case 1}

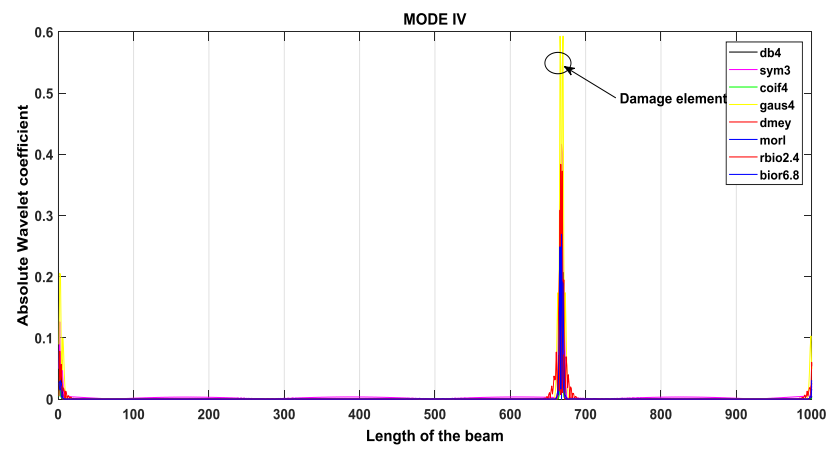

Figure 6. 2D plot of Abs. Coefficient along major axis of the beam for different wavelet families

Figure 6 shows the rotational modes shape data for damage case 1 absolute wavelet coefficient of different wavelets are plotted along major axis of the beam to locate damage; peak magnitude signifies damage location. Fourth mode is slightly less sensitive comparing to the second mode shape.

\subsubsection{Fifth Mode shape for damage case 1 :}

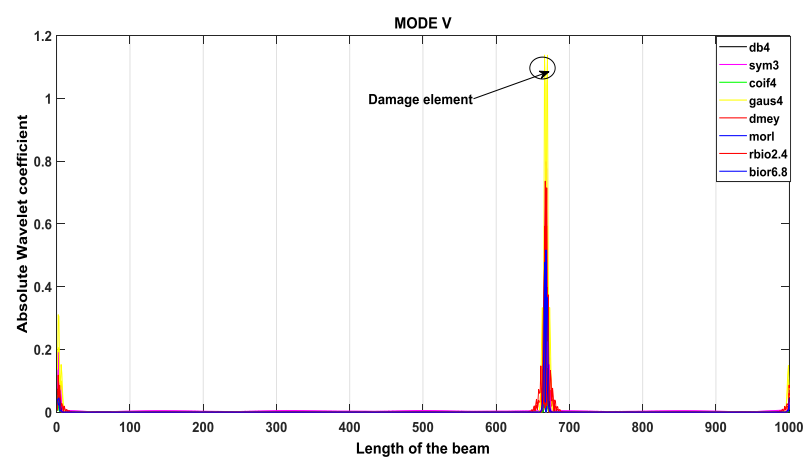

Figure 7. 2D plot of Abs. Coefficient along the length of beam for different wavelet families

Figure 7 shows the rotational modes shape data for damage case 1 absolute wavelet coefficient of different wavelets are plotted along major axis of the beam to locate damage, peak magnitude signifies the damage location. Particularly in fifth mode boundary effect is high so the damage prediction shows fault value because the maximum absolute wavelet coefficients occur near fixed position. Sudden variation in stiffness leads this kind of problem. 
Table 3. Damage prediction sensitivity of first five modes for damage case 1

\begin{tabular}{|c|c|c|c|c|c|}
\hline $\begin{array}{c}\text { Different } \\
\text { Wavelet types }\end{array}$ & $\begin{array}{c}\text { Mode } \\
\text { I }\end{array}$ & $\begin{array}{c}\text { Mode } \\
\text { II }\end{array}$ & $\begin{array}{c}\text { Mode } \\
\text { III }\end{array}$ & $\begin{array}{c}\text { Mode } \\
\text { IV }\end{array}$ & $\begin{array}{c}\text { Mode } \\
\text { V }\end{array}$ \\
\hline Db4 & 668 & 668 & 668 & 668 & 668 \\
\hline Sym3 & 668 & 668 & 668 & 668 & 668 \\
\hline Coif4 & 668 & 668 & 668 & 668 & 668 \\
\hline Gaus4 & 666 & 666 & 2 & 670 & 666 \\
\hline Dmey & 667 & 667 & 667 & 667 & 667 \\
\hline Morl & 667 & 667 & 667 & 667 & 667 \\
\hline Rbio2.4 & 668 & 668 & 668 & 668 & 668 \\
\hline Bior6.8 & 668 & 668 & 668 & 668 & 668 \\
\hline
\end{tabular}

Table 3. Explains the different wavelets are tested for all the mode shapes and damage detection sensitivity comparisons are tabulated for suitable mode selection. From the table first mode and fifth mode is not effective in damage detection for this beam structure. Hence in this study second mode only taken for the entire study, same input is used for different wavelets and the damage location and coefficient values are calculated and it was compared to the original damage criteria and chooses the best wavelet for beam damage detection problem.

Table 4. Damage detection using second mode shape data for damage case 1

\begin{tabular}{|c|c|c|c|}
\hline $\begin{array}{c}\text { Different } \\
\text { Wavelet types }\end{array}$ & $\begin{array}{c}\text { Actual } \\
\text { Element }\end{array}$ & $\begin{array}{c}\text { Predicted } \\
\text { Element }\end{array}$ & $\begin{array}{c}\text { Absolute } \\
\text { Wavelet } \\
\text { coefficient }\end{array}$ \\
\hline Db4 & 666 & 668 & 0.1298 \\
\hline Sym3 & 666 & 668 & 0.1623 \\
\hline Coif4 & 666 & 668 & 0.0765 \\
\hline Gaus4 & 666 & 666 & 0.2314 \\
\hline Dmey & 666 & 667 & 0.1497 \\
\hline Morl & 666 & 667 & 0.0748 \\
\hline Rbio2.4 & 666 & 668 & 0.1229 \\
\hline Bior6.8 & 666 & 668 & 0.1051 \\
\hline
\end{tabular}

Table 4. Shows all the different wavelets damage detection sensitivity for damage case 1 and maximum wavelet coefficient is obtained for damage severity it is very sensitive

\subsubsection{Single damage location for damage case $2 \& 3$}

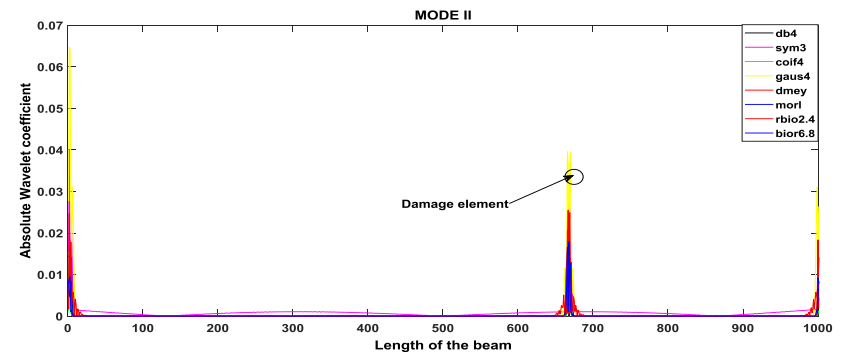

Figure 8. 2D plot of Abs. Coefficient along major axis of the beam for different wavelet families
Figure 8 shows the rotational modes shape data for damage case 2 absolute wavelet coefficients of different wavelets are plotted along major axis of the beam to locate the damage; peak magnitude signifies the damage location. Without fundamental data mode II data is effective to detect the damage but quantifying the severity. Sym3, Dmey, and Bior 6.8 these wavelets are having less influence on boundary effect so these wavelets are considered to be optimum for this problem. Table.5 shows all the different wavelets damage detection sensitivity for damage case 2 and maximum wavelet coefficient is obtained for damage severity it is very sensitive. Second mode fixed for single element damage analysis and fifth mode is fit for multi damage detection case.

Table 5. Damage detection using second mode shape data for damage case 2

\begin{tabular}{|c|c|c|c|}
\hline $\begin{array}{c}\text { Different } \\
\text { Wavelet types }\end{array}$ & $\begin{array}{c}\text { Actual } \\
\text { Element }\end{array}$ & $\begin{array}{c}\text { Predicted } \\
\text { element }\end{array}$ & $\begin{array}{c}\text { Absolute } \\
\text { Wavelet } \\
\text { coefficient }\end{array}$ \\
\hline Db4 & 666 & 668 & 0.0222 \\
\hline Sym3 & 666 & 2 & 0.0400 \\
\hline Coif4 & 666 & 668 & 0.0130 \\
\hline Gaus4 & 666 & 2 & 0.0647 \\
\hline Dmey & 666 & 667 & 0.0255 \\
\hline Morl & 666 & 669 & 0.0128 \\
\hline Rbio2.4 & 666 & 668 & 0.0210 \\
\hline Bior6.8 & 666 & 668 & 0.0179 \\
\hline
\end{tabular}

Damage case $1 \& 2$ only this algorithm works properly with the help of only damaged data.

\subsection{Module 2: Difference data of undamaged and damaged beam structure}

Wavelets are effective tool in signal analysis to locate the redundancy which is present in the signal. The nonlinearity present in the signal is only damage location but near by the boundary due to sudden change in the stiffness also create large peak near boundary location. Sometimes the boundary effect will be high enough to lead the damage detection algorithm in the wrong path.

\subsubsection{Damage case 1:}

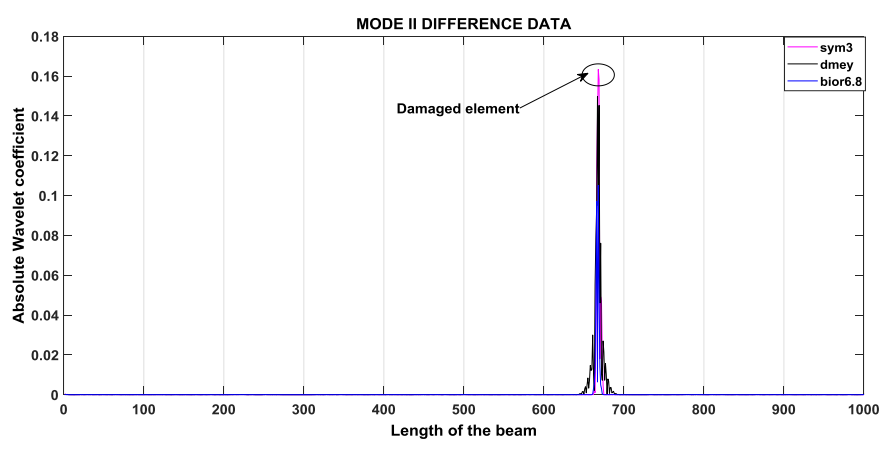

Figure. 9 (a). 2D plot of Abs. Coefficient along major axis of the beam for different wavelet families 


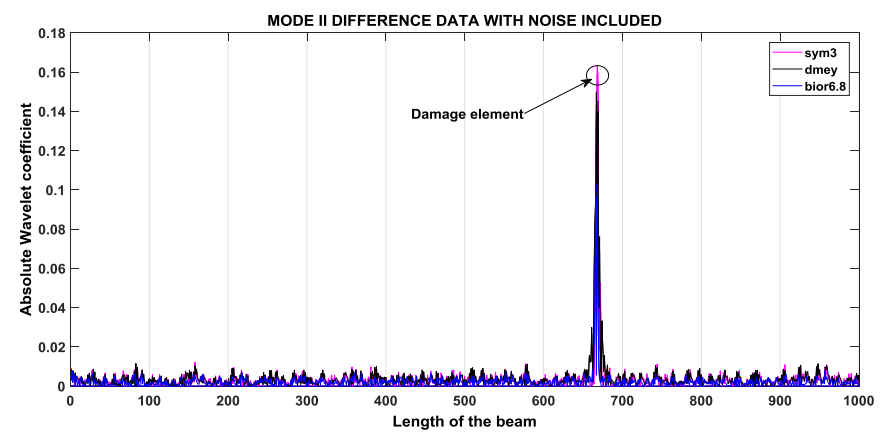

Figure.9 (b). 2D plot of Abs. Coefficient along major axis of the beam for different wavelet families with noise included

Table 5. Damage detection using second mode shape data for damage case 1

\begin{tabular}{|c|c|c|c|}
\hline $\begin{array}{c}\text { Different } \\
\text { Wavelet }\end{array}$ & $\begin{array}{c}\text { Damaged } \\
\text { element }\end{array}$ & $\begin{array}{c}\text { Predicted } \\
\text { element }\end{array}$ & $\begin{array}{c}\text { Max. Abs } \\
\text { coefficient }\end{array}$ \\
\hline Sym3 & 666 & 668 & 0.1586 \\
\hline dmey & 666 & 667 & 0.1499 \\
\hline Bior6.8 & 666 & 668 & 0.1028 \\
\hline
\end{tabular}

Figure 9 (a) shows the rotational mode shapes difference data's absolute wavelet coefficient of sym3, Dmey \& bior6.8 wavelets are plotted along major axis of the beam to locate damage, and peak magnitude signify damage location. Figure 9 (b) shows the damage detection sensitivity with noise included. The table 5 shows the damage detection performances of sym3, Dmey and bior6.8 with noise present

\subsubsection{Damage case 2:}

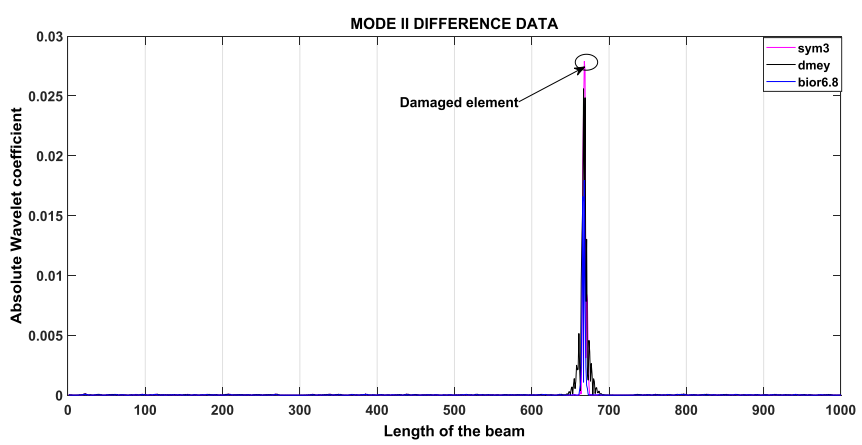

Figure 10(a). 2D plot of Abs. Coefficient along major axis of the beam for different wavelet families

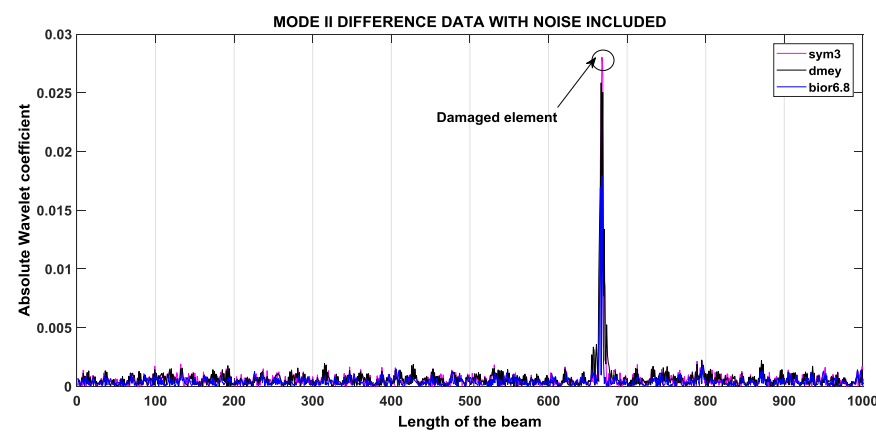

Figure 10(b). 2D plot of Abs. Coefficient along major axis of the beam for different wavelet families with noise included
Table 6. Damage detection using second mode shape data for damage case 2

\begin{tabular}{|c|c|c|c|}
\hline $\begin{array}{c}\text { Different } \\
\text { Wavelet }\end{array}$ & $\begin{array}{c}\text { Damaged } \\
\text { element }\end{array}$ & $\begin{array}{c}\text { Predicted } \\
\text { element }\end{array}$ & $\begin{array}{c}\text { Max. Abs } \\
\text { coefficient }\end{array}$ \\
\hline Sym3 & 666 & 668 & 0.0280 \\
\hline Dmey & 666 & 667 & 0.0258 \\
\hline Bior6.8 & 666 & 668 & 0.0179 \\
\hline
\end{tabular}

Figure 10(a) shows the rotational mode shapes difference data's absolute wavelet coefficient of sym3, Dmey \& bior6.8 wavelets are plotted along major axis of the beam to locate damage, and peak magnitude signify damage location. Figure 10(b) shows the damage detection sensitivity with noise included. The table 6 shows the damage detection performances of sym3, Dmey and bior6.8 with noise present

\subsubsection{Damage case 3:}

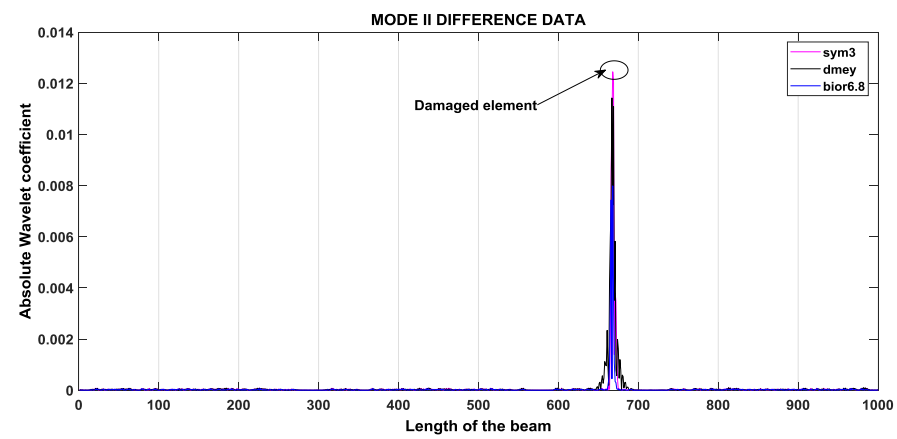

Figure 11(a). 2D plot of Abs. Coefficient along major axis of the beam for different wavelet families

Table 7. Damage detection using second mode shape data for damage case 3

\begin{tabular}{|c|c|c|c|}
\hline $\begin{array}{c}\text { Different } \\
\text { Wavelet }\end{array}$ & $\begin{array}{c}\text { Damaged } \\
\text { element }\end{array}$ & $\begin{array}{c}\text { Predicted } \\
\text { element }\end{array}$ & $\begin{array}{c}\text { Max. Abs } \\
\text { coefficient }\end{array}$ \\
\hline Sym3 & 666 & 668 & 0.0124 \\
\hline Dmey & 666 & 667 & 0.0114 \\
\hline Bior6.8 & 666 & 668 & 0.0080 \\
\hline
\end{tabular}

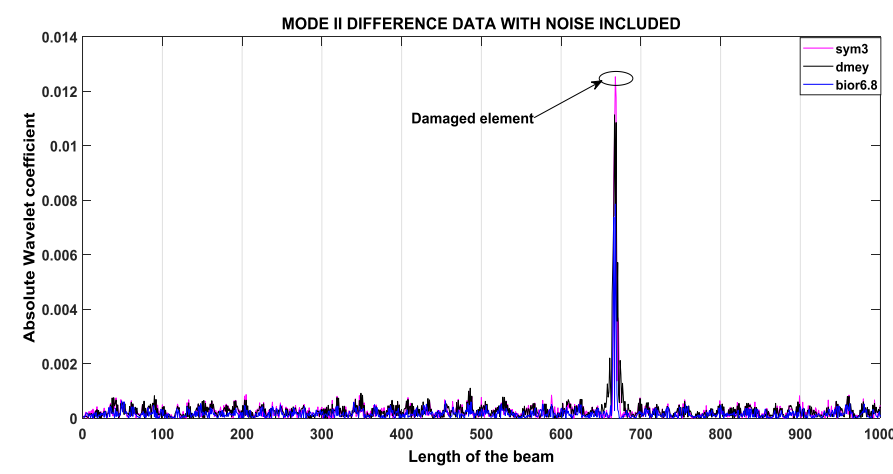

Figure 11(b). 2D plot of Abs. Coefficient along major axis of the beam for different wavelet families with noise included 
Figure 11(a) shows the rotational mode shapes difference data's absolute wavelet coefficient of sym3, Dmey \& bior6.8 wavelets are plotted along major axis of the beam to locate the damage, and peak magnitude signify damage location. Figure 11(b) shows the damage detection sensitivity with noise included. The table 7 shows the damage detection performances of sym3, Dmey and bior6.8 with noise present

\subsubsection{Damage case 4:}

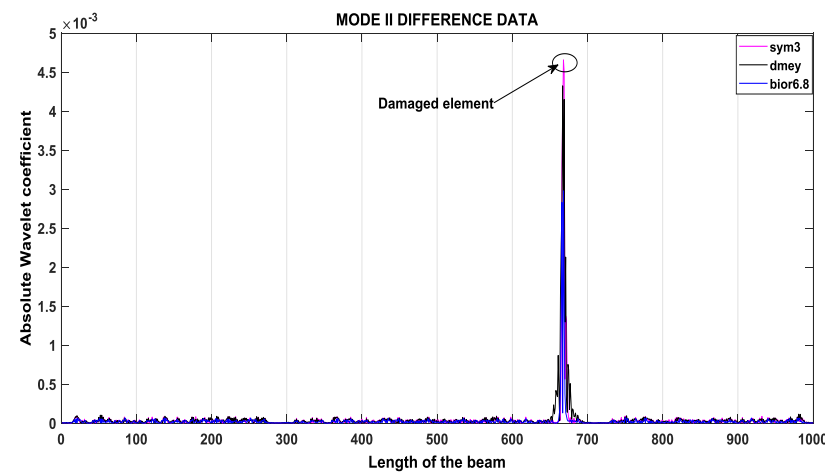

Figure 12(a). 2D plot of Abs. Coefficient along major axis of the beam for different wavelet families

Table 8. Damage detection using second mode shape data for damage case 4

\begin{tabular}{|c|c|c|c|}
\hline $\begin{array}{c}\text { Different } \\
\text { Wavelet }\end{array}$ & $\begin{array}{c}\text { Damaged } \\
\text { element }\end{array}$ & $\begin{array}{c}\text { Predicted } \\
\text { element }\end{array}$ & $\begin{array}{c}\text { Max. Abs } \\
\text { coefficient }\end{array}$ \\
\hline Sym3 & 666 & 668 & 0.0047 \\
\hline Dmey & 666 & 667 & 0.0043 \\
\hline Bior6.8 & 666 & 668 & 0.0030 \\
\hline
\end{tabular}

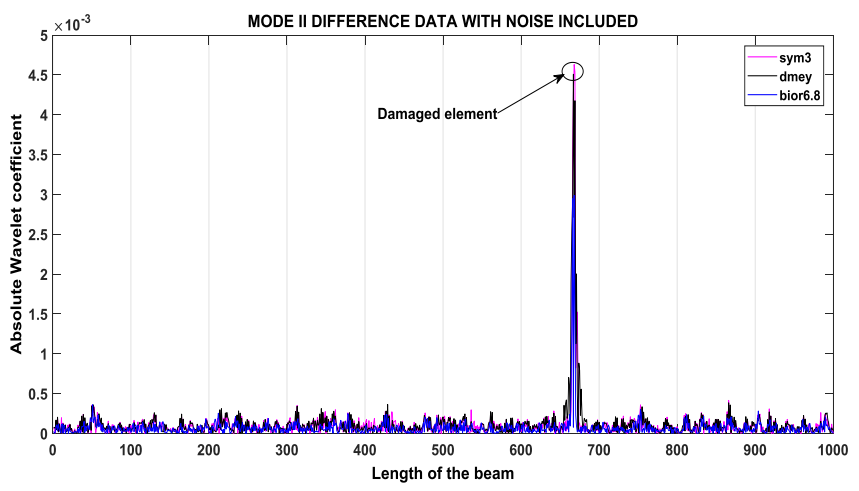

Figure 12(b). 2D plot of Abs. Coefficient along major axis of the beam for different wavelet families with noise included

Figure 12(a) shows the rotational mode shapes difference data's absolute wavelet coefficient of sym3, Dmey \& bior6.8 wavelets are plotted along major axis of the beam to locate damage, and peak magnitude signify damage location. Figure 12(b) shows the damage detection sensitivity with noise included. The table 8 shows the damage detection performances of sym3, Dmey and bior6.8 with noise present

\subsubsection{Damage case 5:}

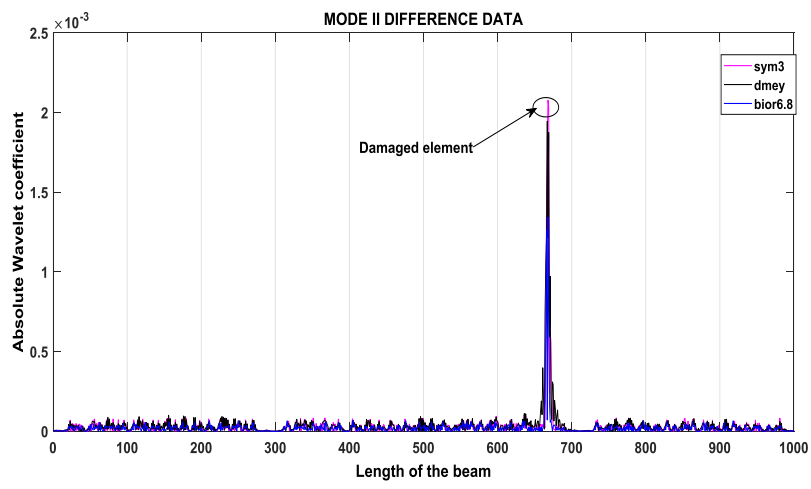

Figure 13(a). 2D plot of Abs. Coefficient along major axis of the beam for different wavelet families

Table 9. Damage detection using second mode shape data for damage case 5

\begin{tabular}{|c|c|c|c|}
\hline $\begin{array}{c}\text { Different } \\
\text { Wavelet }\end{array}$ & $\begin{array}{c}\text { Damaged } \\
\text { element }\end{array}$ & $\begin{array}{c}\text { Predicted } \\
\text { element }\end{array}$ & $\begin{array}{c}\text { Max. Abs } \\
\text { coefficient }\end{array}$ \\
\hline Sym3 & 666 & 668 & 0.0021 \\
\hline Dmey & 666 & 667 & 0.0019 \\
\hline Bior6.8 & 666 & 668 & 0.0013 \\
\hline
\end{tabular}

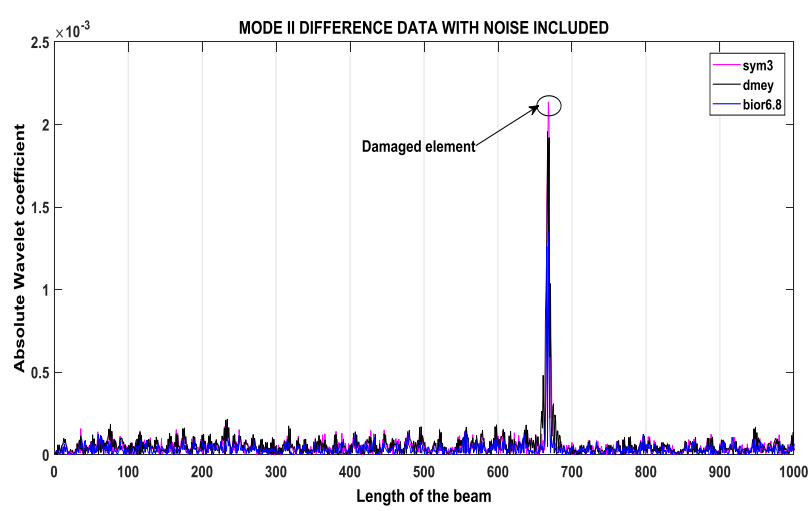

Figure 13(b). 2D plot of Abs. Coefficient along major axis of the beam for different wavelet families with noise included

Figure 13(a) shows the rotational mode shapes difference data's absolute wavelet coefficient of sym3, Dmey \& bior6.8 wavelets are plotted along the major axis of the beam to locate damage, and peak magnitude signify damage location. Figure 13(b) shows the damage detection sensitivity with noise included. After the noise inclusion doesn't lose its sensitivity. The table 9 shows the damage detection performances of sym3, Dmey and bior6.8 without noise present. 


\subsubsection{Damage case 6:}

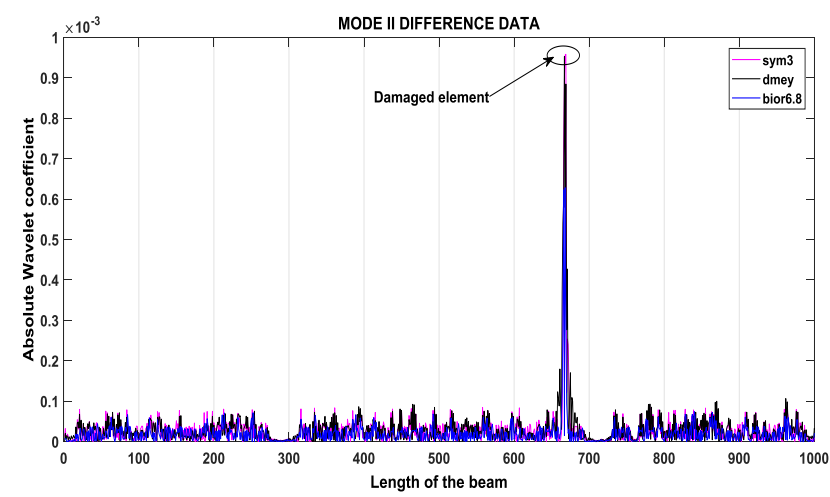

Figure 14(a). 2D plot of Abs. Coefficient along major axis of the beam for different wavelet families

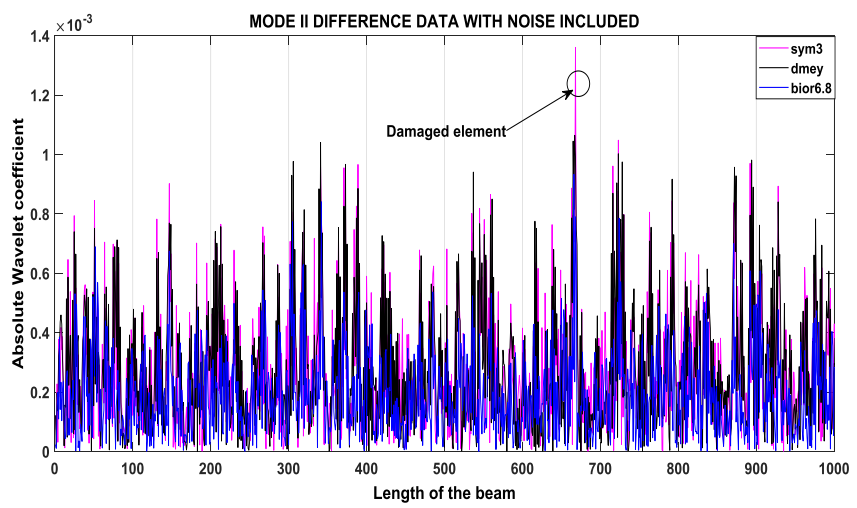

Figure 14(b). 2D plot of Abs. Coefficient along major axis of the beam for different wavelet families with noise included

Table 10. Damage detection using second mode shape data for damage case 6

\begin{tabular}{|c|c|c|c|}
\hline $\begin{array}{c}\text { Different } \\
\text { Wavelet }\end{array}$ & $\begin{array}{c}\text { Damaged } \\
\text { element }\end{array}$ & $\begin{array}{c}\text { Predicted } \\
\text { element }\end{array}$ & $\begin{array}{c}\text { Max. Abs } \\
\text { coefficient }\end{array}$ \\
\hline Sym3 & 666 & 668 & 0.0014 \\
\hline Dmey & 666 & 667 & 0.0011 \\
\hline Bior6.8 & 666 & 668 & $9.33 \mathrm{e}-4$ \\
\hline
\end{tabular}

Figure 14(a) shows the rotational mode shapes difference data's absolute wavelet coefficient of sym3, Dmey \& bior6.8 wavelets are plotted along major axis of the beam to locate damage, and peak magnitude signify damage location. Figure 14(b) shows the damage detection sensitivity with noise included. After noise included wavelet algorithm loses its damage detecting sensitivity. The table 10 shows the damage detection performances of sym3, Dmey and bior6.8 without noise

\subsubsection{Damage case 7:}

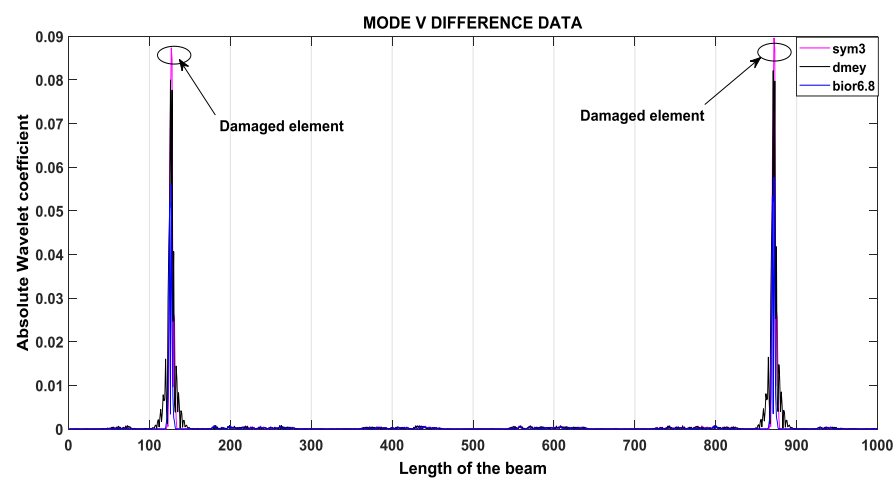

Figure 15(a). 2D plot of Abs. Coefficient along major axis of the beam for different wavelet families

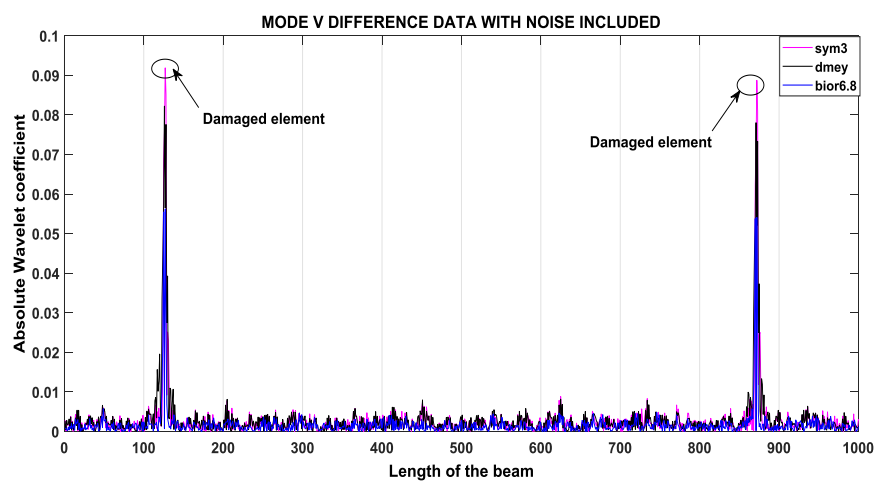

Figure 15(b). 2D plot of Abs. Coefficient along major axis of the beam for different wavelet families with noise included

Figure 15(a) shows the rotational mode shapes difference data's absolute wavelet coefficient of sym3, Dmey \& bior6.8 wavelets are plotted along major axis of the beam to locate damage, and peak magnitude signify damage location. Figure 15 (b) shows the damage detection sensitivity with noise included.

For double element damage case second mode is detecting the damage location but the magnitude of the wavelets it is varying even the damage severity is same so consider the fault here consider the fifth mode because its absolute coefficient values are very much nearer comparing to all other modes. So fifth mode is optimum for multi damage is detecting.

When noise added to the difference data all damage cases are detecting and estimating the damage severity except two damage cases $6 \& 8$, Damage cases 6 it is the least damage severity so it doesn't detect the damage, On the other hand damage case 8 is triple damage, due to noise it won't be able to detect the damage location. 


\subsubsection{Damage case 8:}

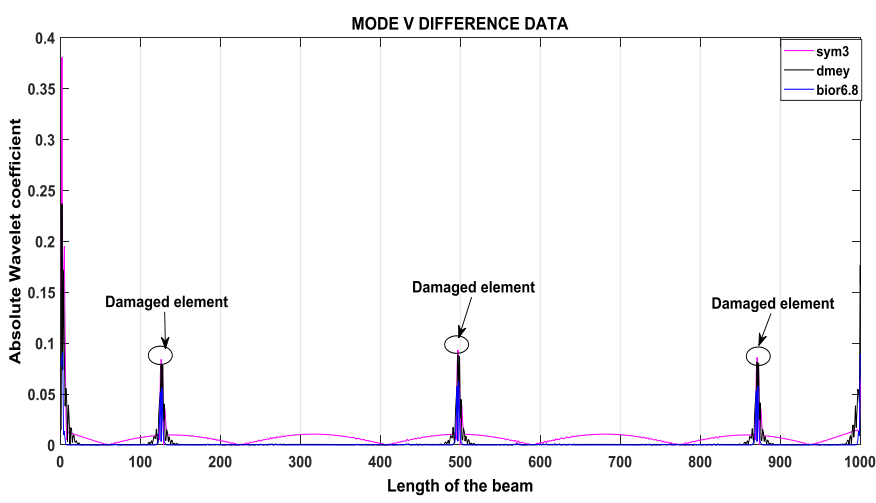

Figure 16 (a). 2D plot of Abs. Coefficient along major axis of the beam for different wavelet families

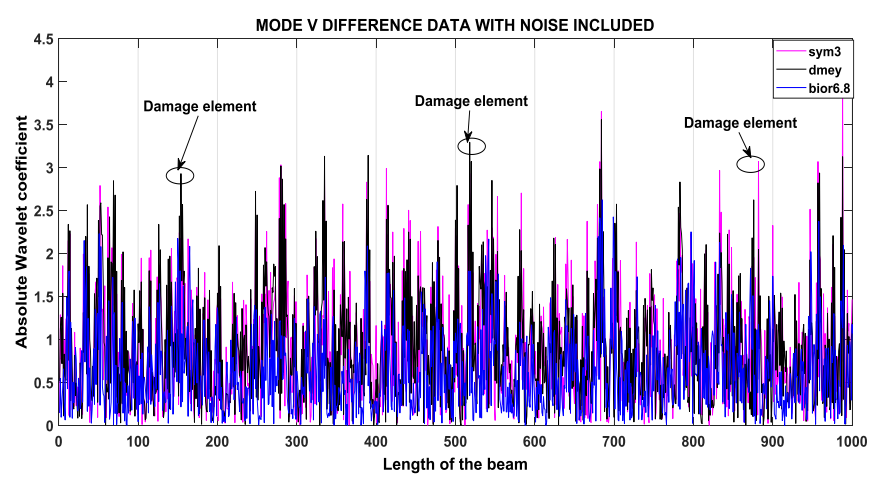

Figure 16 (b). 2D plot of Abs. Coefficient along major axis of the beam for different wavelet families with noise included

Figure 16 (a) shows the rotational mode shapes difference data's absolute wavelet coefficient of sym3, Dmey \& bior6.8 wavelets are plotted along major axis of beam to locate damage, and peak magnitude signify damage location. Figure 16 (b) shows the damage detection sensitivity with noise included. When the noise is added for triple element damage prediction is loses its sensitivity in damage detection algorithm. Especially here fifth mode is considered optimum to find the multi damage before the noise inclusion the algorithm is detecting accurately but adding noise it loses its sensitive in damage detection.

\section{CONCLUSION:}

The objective of this paper is to evaluate the effectiveness of the different wavelet families in Timoshenko beam damage detection. Optimum mode selection and optimum wavelet selection are studied. Importance of difference data in wavelet-based damage detection to avoid boundary effect during the analysis process explored. Boundary near damage location \& double and triple damage location detection algorithm developed in Mat lab to find the damage spot and characterize the damage.

\section{Module 1:}

Damage case 1 rotational displacement data for first five modes processed through wavelet damage detection algorithm, all modes are detecting the damage location but in third mode the peak occur near by the boundary so the algorithm failed to detect the damage location, considering the damaged element prediction and comparing absolute wavelet coefficient value for all modes to find the optimum mode, in this study mode is optimum for single element damage. Fifth mode is optimum for double (Damage case 7) and triple (Damage Case 8) element damage. Without using the fundamental data damage detection algorithm sensitivity is high because here the maximum absolute coefficient value occurs in damage location damage case $1,2,7 \& 8$ and damage detection sensitivity is moderate for damage case 3, 4, here peak is occur in the damage location but the maximum absolute value produce near by the boundary so the algorithm is miss lead to locate the damage put anyway this peak will point out the damage location. Damage detection sensitivity is very less for damage case $5 \& 6$. Here lot of peaks arising due to the damage size is low. During this analysis the performances of different wavelet families are studied, with their absolute coefficient which is predicted by the damage location is calculated and compared over with others. Sym3, bior6.8, Dmey wavelets in order to belong the Symmlets family, Biorthogonal family, Dmeyer family, these three families are best in damage detection for without using fundamental, so these three wavelets are used in module 2 to study damage detection problem for using difference data.

\section{Module 2:}

Contrast information between intact rotational mode shape and damaged rotational mode shape to contemplate the execution of sym3, Dmey, bior6.8 wavelets. Changes in rotational mode shapes because of the damage present, information spoke to here in a numerical analysis demonstrates. The after effects of the beam display exhibit the convenience of the adjustments in the rotational mode shape as an indicative parameter in recognizing and finding damage concerning the beam with both end clamped conditions.

Using the difference data in damage detection algorithm sensitivity is high for all damage cases even adding Gaussian white noise level SNR 20 is also won't affect the algorithm except damage case 6 , because it is the least damage severity so the algorithm detects accurately before adding noise after adding noise the algorithm loses its sensitivity. According to the performance of wavelets sym3 is producing larger absolute coefficient value and Dmeyer wavelets are moderate in absolute wavelet coefficient value, Biorthogonal wavelet absolute wavelet coefficient is low. Orthogonal properties with FIR (Finite Impulse Response) filters make Symmlet wavelet is best comparing to other wavelet families in damage detection on Timoshenko beam damage detection. Dmeyer wavelet is symmetric and it is related to both orthogonal and Biorthogonal properties so it becomes moderate performance comparing to other wavelet families. Bior6.8 wavelet is symmetric but not orthogonal so its effective is less comparing to Symmlet and Dmey. This method is applicable for complicated structure, but experimentally collect lot of data's is a challenging task. 


\section{REFERENCES:}

[1] Cawley P, Adams RD. The location of defects in structures from measurements of natural frequencies, Journal of strain analysis, Vol.14 No.2, 1979

[2] Salawu OS, Williams C. Structural Damage Detection Using Experimental Modal Analysis-A Comparison of Some Methods, In Proc. of 11th International Modal Analysis Conference, pp.254-260, 1993

[3] Quan W, Xiaomin, D. Damage detection with spatial wavelets. International Journal of Solids and Structures, Vol. 36, pp.3443-3468, 1999

[4] Boulahbal et al. Amplitude and phase wavelet maps for the detection of cracks in geared systems. Mechanical Systems and Signal Processing, Vol. 13 No.3, pp.423436, 1999

[5] Ratcliffe C P. Frequency and curvature based experimental method for locating damage in structures, Journal of Vibration Acoustic, Vol.122, pp.324329,2000

[6] Tong et al. Sensitivity analysis of crack detection in beams by wavelet technique. International Journal of Mechanical Sciences, Vol.43, pp.2899-2910, 2001

[7] Douka et al. Crack identification in beams using wavelet analysis. International Journal of Solids and Structures Vol.40, pp.3557-3569, 2003

[8] Hani M, Hansang K. Damage Detection in Concrete by Fourier and Wavelet Analyses. Journal of Engineering Mechanics, Vol.129, No. 5, 2003

[9] Chang C, Chen W. Vibration damage detection of a Timoshenko beam by spatial wavelet based approach. Applied Acoustics, Vol. 64, pp.1217-1240, 2003

[10] Loutridisa et al. Crack identification in double-cracked beams using wavelet analysis, Journal of Sound and Vibration, Vol. 277, pp.1025-1039, 2004

[11] Chang C, Chen W. Detection of the location and size of cracks in the multiple cracked beam by spatial wavelet based approach. Mechanical Systems and Signal Processing, Vol. 19, pp.139-155, 2005

[12] Rucka M, Wilde K. Application of continuous wavelet transform in vibration based damage detection method for beams and plates. Journal of Sound and Vibration, Vol. 297, pp.536-550, 2006

[13] Reddy et al. Detection and localization of damage in bridge model by spatial wavelet based approach. International Journal of Modeling, Identification and Control, Vol.3, No.2, 2008

[14] Gokdag H, Kopmaz O. A new damage detection approach for beam-type structures based on the combination of continuous and discrete wavelet transforms. Journal of Sound and Vibration, Vol.324, pp.1158-1180, 2009
[15] Zhong SS, Oyadiji SO. Crack detection in simply supported beams using stationary wavelet transform of modal data. Structural Control Health Monitoring, Vol.18, pp.169-190, 2011

[16] Reddy DM, Swarnamani S. Damage Detection and Identification in Structures by Spatial Wavelet Based Approach. International Journal of Applied Science and Engineering Vol.1, pp.69-87, 2012

[17] Reddy DM, Swarnamani S. Application of the FRF curvature energy damage detection method to plate like structures. World Journal of Modeling and Simulation Vol. 8, pp.147-153, 2012

[18] Jaiswal NG, Pande DW. Sensitizing the mode shapes of beam towards damage detection using curvature and wavelet transform. International journal of scientific \& technology research vol.4, No.04, 2015

[19] Diaferio M, Sepe V. Modal identification of damaged frames', Structural Control Health Monitoring. Vol.23, pp. 82-102.2016

[20] Dogra A, Goyal B and Agarwal S. Performance comparison of different wavelet families based on bone vessel fussion. Assian journal of Pharmaceutics, Vol 10(4).2013 